\title{
MODELLING AND EXPERIMENTAL INVESTIGATION OF WASTE TYRE PYROLYSIS PROCESS IN A LABORATORY REACTOR
}

\begin{abstract}
Leszek Rudniak, Piotr M. Machniewski*
Warsaw University of Technology, Faculty of Chemical and Process Engineering, ul. Waryńskiego 1, Warsaw, Poland

A mathematical model of waste tyre pyrolysis process is developed in this work. Tyre material decomposition based on a simplified reaction mechanism leads to main product lumps: noncondensable (gas), condensable (pyrolytic oil) and solid (char). The model takes into account kinetics of heat and mass transfer in the grain of the shredded rubber material as well as surrounding gas phase. The main reaction routes were modelled as the pseudo-first order reactions with a rate constant calculated from the Arrhenius type equation using literature values of activation energy determined for main tyre constituents based on TG/DTG measurements and tuned pre-exponential parameter values obtained by fitting theoretical predictions to the experimental results obtained in our laboratory reactor. The model was implemented within the CFD software (ANSYS Fluent). The results of numerical simulation of the pyrolysis process revealed non-uniformity of sample's porosity and temperature. The simulation predictions were in satisfactory agreement with the experimentally measured mass loss of the tyre sample during pyrolysis process investigated in a laboratory reactor.
\end{abstract}

Keywords: waste tyres, pyrolysis, kinetics, CFD

\section{INTRODUCTION}

Rubber wastes such as used car tyres are refractory to quick self-decomposition and biodegradation. It is necessary to process these wastes in order to prevent their accumulation in landfill sites. The common approach is co-incineration of tyre wastes as an alternative fuel in cement or lime kilns, blast furnaces, steam boilers etc. Another possible processing route is pyrolysis, which not only allows for partial recovery of energy but also for utilisation of the by-products (material recycling) and can be carried out in the environment-friendly way. The pyrolysis products include volatile compounds, which can be partly condensed resulting in liquid (oil) and gaseous fractions. The solid remainder (approx. $30-40 \%$ of tyre mass), mostly composed of char, can be recycled and utilised after purification for manufacture of new tyres. These potential advantages of the pyrolysis process attracted many researchers and their efforts to investigate this process in laboratory, pilot plant and industrial scales. The studies of tyre pyrolysis covered processes carried out in fixed and fluidised bed reactors (Kaminsky et al. 2009), spouted bed (Olazar et al. 2008), moving screw bed (Aylón et al. 2010a; 2010b), and rotary kiln reactors. The process is carried out in the atmosphere of inert gases under normal pressure and in vacuum conditions (Lopez et al. 2010) and temperatures typically between $300{ }^{\circ} \mathrm{C}$ and $900{ }^{\circ} \mathrm{C}$. Characteristics and comparison of different reactor types and conditions for the tyre pyrolysis process were broadly and synthetically presented in many review papers (e.g. Wilson, 2013; Antoniou and Zabaniotou, 2013). The published results indicate increase of non-condensable gaseous products typically from $4-5 \%$ to $25-30 \%$ if the final temperature in the reactor is increased from $350-400{ }^{\circ} \mathrm{C}$ to $700-900{ }^{\circ} \mathrm{C}$. This is most probably caused by cracking of heavy pyrolysis products 
into lower molecular mass products (at the higher temperatures). Kinetics of the pyrolysis reaction is in most cases determined based on derivative thermogravimetric (TG/DTG) analysis. The resulting curves of sample mass weight loss rate exhibit usually 2 or 3 peaks, which are said to correspond to main constituents of tyre (elastomers and plasticizers) decomposing at different temperatures. The kinetics of mass loss during TG measurements is usually described by Arrhenius type equation. The paper by Queck and Balasubramanian (2012) extensively reviews many research efforts connected with modelling of tyre pyrolysis and interpretation of DTG measurements. When the size of a tyre sample is above few millimetres additional complications may arise due to possible mass and heat transfer resistances and inhomogeneity of the tyre chip during pyrolysis.

Most publications reporting CFD approach to simulate pyrolysis of solids (mostly biomass) focus on fluidised bed reactors (see e.g. Lam et al., 2012) or conical spouted beds (Niksiar and Sohrabi, 2014) using models where particulate (solid) and gas phases are treated as pseudo-homogeneous continua coupled with interfacial exchange terms in the balance equations for momentum, mass and energy. However, the number of publications dealing with tyre pyrolysis is very low. An example might be the work of Mtui (2013) on CFD modelling of devolatilization and combustion of shredded tires and pine wood in rotary cement kilns, or the work of Bianchi et al. (2014) on CFD modelling of pyrolysis of the whole tyre focused on optimal design of the furnace and gas collector geometry.

This work is focused on applying CFD tools for modelling of pyrolysis process of inhomogeneous tyre chips of $1 \mathrm{~cm}$ in size (typical for industrial tyre cutters) with potential application of this methodology to fixed or moving bed pyrolysis reactors.

\section{KINETIC MODEL OF TYRE PYROLYSIS}

The mechanism of reactions occurring during pyrolysis is very complex. Therefore a simplified approach based on lumped kinetic parameters is proposed by many researchers (cf. e.g. Aylón et al. 2005; Olazar et al. 2008; Miranda et al. 2013). The model used in our previous work (Machniewski et al., 2016) is based on simplified pyrolysis reaction (Eq. 1) where $f$ denotes mass yield of a given product.

$$
P \rightarrow f_{G} G+f_{L} L+f_{S} S
$$

The products were segregated into three different lumps depending on their state after cooling: noncondensing gases $(G)$, condensing vapours $(L)$ and solid reminder $(S)$.

The yields of gaseous products $\left(f_{G}\right)$ and liquid (pyrolytic oil) products $\left(f_{L}\right)$ depend on pyrolysis process parameters (temperature, heating rate, pressure etc.) and the composition of the raw material (tyre). The published experimental results of tyre pyrolysis indicate $60 \%-70 \%$ mass loss attributed to volatile products, including 5-20\% of mass loss due to noncondensable gaseous products (Wilson, 2013; Antoniou and Zabaniotou, 2013). According to the results of Miranda et al.(2013) obtained during experiments carried out in an autoclave heated to $350{ }^{\circ} \mathrm{C}-450{ }^{\circ} \mathrm{C}$, the fraction of gaseous (noncondensable) products was $5 \%$. The amount of gaseous products usually increases with the temperature rise. Olazar et al. (2008) investigated pyrolysis of $1-2 \mathrm{~mm}$ tyre particles in a fluidised bed and observed a drop of liquid (condensable vapours) products fraction from $65 \%$ to $63 \%$ and a growth of gaseous fraction from $1.5 \%$ to $2.7 \%$ in the temperature range of $425{ }^{\circ} \mathrm{C}-610{ }^{\circ} \mathrm{C}$.

A higher growth of gaseous fraction, from $5 \%$ to $12 \%$ in the temperature range of $400{ }^{\circ} \mathrm{C}-600{ }^{\circ} \mathrm{C}$, was observed by Cherbański et al. (2016). The authors also found that the total mass loss increased from $53 \%$ to $63 \%$ within this temperature range. 
As tyres are usually composed of different kinds of elastomers, plasticizers and fillers (carbon black, silica etc.), the kinetics of pyrolysis can be assumed as a sum of thermal decomposition reaction rates $\left(r_{i}\right)$ for each component according to Arrhenius type equation and the first order kinetics (Eq. 2):

$$
r_{P}=\sum_{i} r_{i}=\sum_{i} A_{i} \exp \left(-\frac{E_{i}}{R T}\right) X_{i}
$$

Then the total rate of volatile production can be expressed as:

$$
r_{V}=\sum_{i}\left(f_{L, i}+f_{G, i}\right) r_{i}=\sum_{i} f_{G+L, i} r_{i}
$$

It is assumed here that samples of the tyre, used in the experimental part of this work, are composed of one elastomer type (styrene-butadiene rubber) and a plasticizer oil. The initial content of the plasticiser (oils) in the tyre is typically $10 \%-20 \%$.

Kinetic parameters in Eq. 2 for these components used in subsequent calculations are shown in Table 1. The parameters based on the TG/DTG measurements by Yang et al. (1995), which are also shown in Table 1, were tuned for the purpose of this work by adjusting the values of $A$ used for calculation of relative mass loss of the sample based on a simplified model fitted to the mass loss measured in the laboratory reactor used in this work. The values of activation energies $E$ were assumed after Yang et al. (1995). The simplified model (cf. Machniewski et al., 2016) was based on an assumption of conductive heat transfer in a spherical particle of variable porosity, being heated in a flow reactor similar to that used in this work and described in the experimental part.

Table 1. Kinetic parameters in Eq. (2) used in this work

\begin{tabular}{|l|c|c|c|}
\hline \multicolumn{1}{|c|}{ Component of tyre } & $\begin{array}{c}A[1 / \mathrm{min}] \\
\text { (this work) }\end{array}$ & $\begin{array}{c}A[1 / \mathrm{min}] \\
\text { (Yang et al. 1995) }\end{array}$ & $\begin{array}{c}E[\mathrm{~kJ} / \mathrm{mol}] \\
\text { (Yang et al. 1995) }\end{array}$ \\
\hline plasticiser, oils (A) & $2.01 \times 10^{3}$ & $4.01 \times 10^{4}$ & 49.1 \\
\hline styrene-butadiene rubber (SBR) & $1.08 \times 10^{10}$ & $1.78 \times 10^{10}$ & 152.0 \\
\hline
\end{tabular}

\section{CFD MODELLING OF TYRE PYROLYSIS PROCESS}

The inert gas (nitrogen) and volatile products of tyre pyrolysis can be modelled as a laminar flow fluid zone. Continuity, momentum and energy balance equations for laminar flow are in the following form in the gas phase:

$$
\begin{gathered}
\frac{\partial \rho}{\partial t}+\nabla \cdot(\rho \vec{V})=S_{m} \\
\frac{\partial(\rho \vec{V})}{\partial t}+\nabla \cdot(\rho \vec{V} \vec{V})=\mu \nabla^{2} \vec{V}-\nabla P+\rho \vec{g}+S_{p} \\
\frac{\partial\left(\rho C_{p} T\right)}{\partial t}+\nabla \cdot\left[\vec{V}\left(\rho C_{p} T\right)\right]=\nabla \cdot[k \nabla T]+S_{h}
\end{gathered}
$$

Additionally species equations for gas species take a form:

$$
\frac{\partial\left(\rho Y_{i}\right)}{\partial t}+\nabla \cdot\left[\vec{V}\left(\rho Y_{i}\right)\right]=\nabla \cdot\left[\rho D_{i} \nabla Y_{i}\right]+S_{i}
$$

The above set of equations was solved using the finite volume method (ANSYS ver. 18.0 documentation). In the above equations source terms $S_{i}$ are due to the pyrolysis reaction. Diffusivity of 
the volatile species (treated as a surrogate component) in the gas phase was set as $D=10^{-5} \mathrm{~m}^{2} / \mathrm{s}$. The tire can be modelled as porous media, in which the solid phase is in thermal equilibrium with the gas phase during pyrolysis. ANSYS Fluent solver uses the following equation in order to solve heat transfer in the porous zone:

$$
\begin{gathered}
\left(\rho C_{p}\right)_{\mathrm{pm}}\left(\frac{\partial T_{\mathrm{pm}}}{\partial t}+\vec{V} \cdot \nabla T_{\mathrm{pm}}\right)=\nabla \cdot\left(k_{\mathrm{eff}} \nabla T_{\mathrm{pm}}\right)+S_{h} \\
\left(\rho C_{p}\right)_{\mathrm{pm}}=\left(\rho C_{p}\right)_{s}(1-\gamma)+\left(\rho C_{p}\right)_{V} \gamma \\
k_{\mathrm{eff}}=k_{V} \gamma+k_{s}(1-\gamma)
\end{gathered}
$$

The momentum balance (Equation 5) with the appropriate source term $S_{\mathrm{p}}$ based on Ergun model was used within the porous zone (see ANSYS ver. 18.0 Documentation).

Specific heat and heat conductivity used in the calculations are given in Table 2. The values were assumed according to Yang et al. (1995). The porosity of the rubber sample during pyrolysis was adapted by means of user defined functions (UDF) in Fluent solver according to the mass of solid components in the rubber and overall mass balance in the control volume.

Table 2. Thermal properties used in the calculations after Yang et al. (1995)

\begin{tabular}{|l|c|}
\hline \multicolumn{1}{|c|}{ Parameter } & Value \\
\hline Specific heat of rubber $[\mathrm{kJ} /(\mathrm{kg} \cdot \mathrm{K})]$ & $1.9+3 \times(T-298)$ for $T>298 \mathrm{~K}$ \\
\hline Specific heat of carbon black $[\mathrm{kJ} /(\mathrm{kg} \cdot \mathrm{K})]$ & 1.8 \\
\hline Specific heat of gaseous components $[\mathrm{kJ} /(\mathrm{kg} \cdot \mathrm{K})]$ & 2.4 \\
\hline Heat conductivity of rubber $[\mathrm{W} /(\mathrm{m} \cdot \mathrm{K})]$ & 0.38 \\
\hline Heat conductivity of carbon black $[\mathrm{W} /(\mathrm{m} \cdot \mathrm{K})]$ & 0.2 \\
\hline
\end{tabular}

The density of the gas phase was calculated assuming the ideal gas model. The density of the solid phase (solids, rubber, carbon black) was set as $1100 \mathrm{~kg} / \mathrm{m}^{3}$. Initial porosity of tyre material was assumed as $5 \%$.

\section{EXPERIMENTAL}

In order to validate the presented modelling approach a small series of experiments were performed. A schematic of the experimental setup is shown in Fig 1. Samples of car tyre of an approximately cylindrical shape (diameter $8 \mathrm{~mm}$, height $10 \mathrm{~mm}$ ) were electrically heated in a cylindrical reactor of $20 \mathrm{~mm}$ internal diameter and $100 \mathrm{~mm}$ in length. The reactor was supplied with nitrogen flow of $100 \mathrm{~mL} / \mathrm{min}$ (STP). This flow corresponds to inert gas superficial velocity applicable for a moving screw bed reactor. Also the applied temperature program was aimed to mimic conditions in the entrance section of the reactor. Temperature of the gas phase in the vicinity of the sample was measured during each experiment. The mass of the sample was also measured during the experiments with the aid of a laboratory analytical balance (resolution of $0.1 \mathrm{mg}$ ). The mass of used tyre samples (taken from the sidewall of a passenger car tyre) was approx. $0.4-0.5 \mathrm{~g}$ and average moisture of $0.49 \%$. Their average heat of combustion (measured in a calorimetric bomb) was $37871 \mathrm{~J} / \mathrm{g}$ and average ash remainder was $3 \%$. 


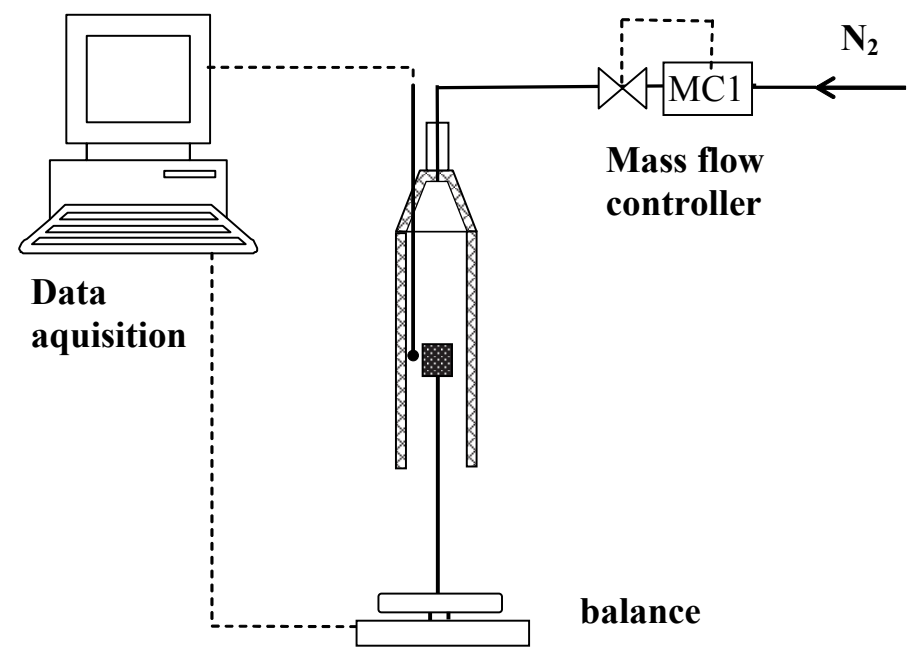

Fig. 1. Scheme of the experimental setup

The following heating programs were performed during experimental runs:

- Heating rate: $13^{\circ} \mathrm{C} / \mathrm{min}$, initial temperature $28^{\circ} \mathrm{C}$, final temperature: $360^{\circ} \mathrm{C}$,

- Heating rate: $26^{\circ} \mathrm{C} / \mathrm{min}$, initial temperature $28^{\circ} \mathrm{C}$, final temperature: $391^{\circ} \mathrm{C}$,

- Heating rate: $22^{\circ} \mathrm{C} / \mathrm{min}$, initial temperature $21^{\circ} \mathrm{C}$, final temperature: $455^{\circ} \mathrm{C}$.

After reaching the final temperature, it was kept at an approximately constant level for approximately 30 minutes.

\section{RESULTS}

The recorded variation of sample's mass for each of the performed experiments is shown in Fig. 2. It was observed that pyrolysis and the volatilisation of tyre starts at the temperature of approximately $250{ }^{\circ} \mathrm{C}-300^{\circ} \mathrm{C}$ when the mass loss is mainly connected with vaporisation of plasticisers and oils. Depending on final temperature the relative total mass loss in the experiments varied between 25 and $65 \%$ (approximately linearly within the investigated final temperature range of $360{ }^{\circ} \mathrm{C}-470{ }^{\circ} \mathrm{C}$ ).

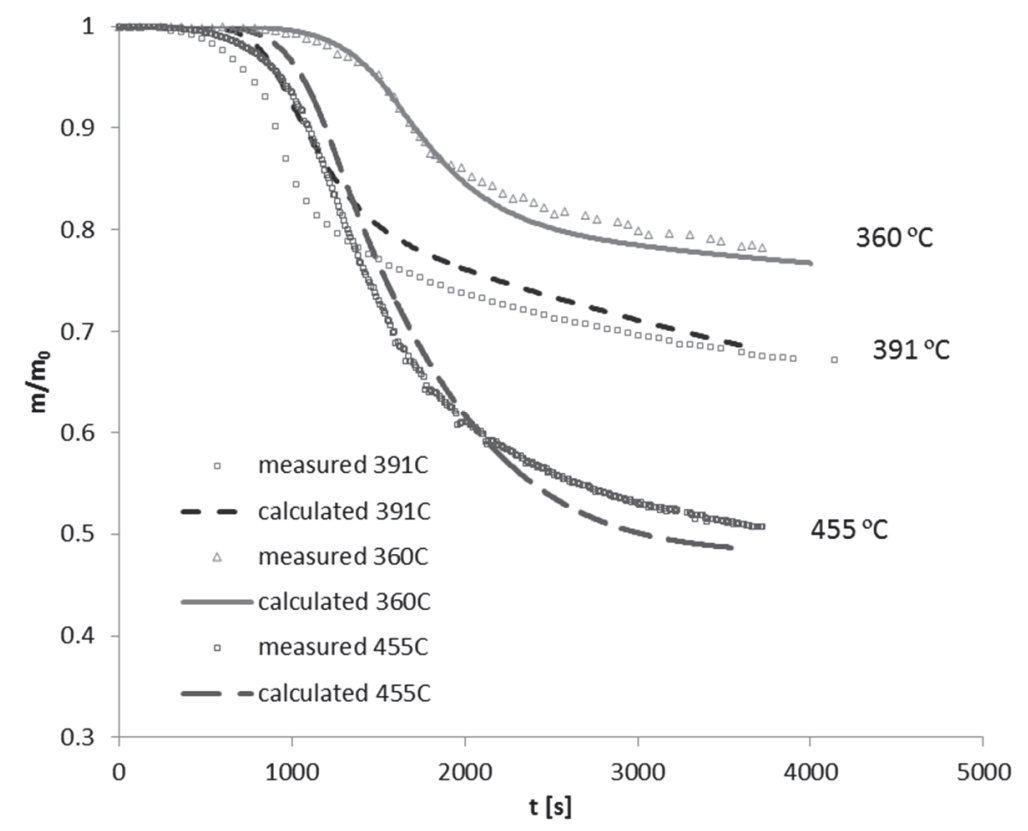

Fig. 2. Variation of relative mass of tyre samples during the pyrolysis experiments (run \#1, \#2, \#3).

Comparison of the CFD simulation results with the measurements 
The measured variation of relative mass of tyre samples during the pyrolysis process can be compared with the calculated one in the course of CFD simulation also shown in Fig. 2. It can be observed that the results of simulation are in fair agreement with the measured mass loss of tyre sample for all the test runs. Nevertheless the best agreement of calculated and measured sample mass variation can be observed in the run with the slowest heating rate (run $\# 1,360^{\circ} \mathrm{C}$ ) when the sample (i.e. temperature and porosity profiles) was more homogeneous during pyrolysis. CFD predictions for the runs corresponding to higher heating rates (run \#2 and run\#3) are somehow delayed compared to the measurements. The run with the highest heating rate (run $\# 2,391^{\circ} \mathrm{C}$ ) exhibits the worst agreement. This is most probably connected with more pronounced non-uniformity (inhomogeneity) of temperature and porosity fields in this case.

CFD calculations which were performed for conditions reflecting the pyrolysis process investigated in the experiments were based on the assumption that the size of the sample remains constant during pyrolysis process simulation. Thus porosity of the tyre sample varied as a result of local volatilisation reaction. Also, it was assumed that non-volatile mineral fillers and carbon black used during tyre manufacture process are treated as part of non-volatile products (solids) produced during pyrolysis. The simulation was performed for tyre samples containing initially $20 \%$ of volatile additives (oil, plasticisers), which was responsible for initial mass loss of the sample. It was assumed that a fraction of the volatile products of the plasticiser (oils) volatilisation/decomposition in the course of pyrolysis is approximately equal to $f_{G+L, A}=1$, and a fraction of volatile pyrolysis products originating from the of styrene-butadiene rubber decomposition as $f_{G+L, S B R}=0.4$.

The calculated temperature contours in the reactor and tyre sample for run \#3 (final temperature $=445^{\circ} \mathrm{C}$ ) at the time instants $t=800 \mathrm{~s}$ and $t=1500 \mathrm{~s}$ are shown in Fig. 3. The chosen times correspond to the initial stage of the pyrolysis process $(t=800 \mathrm{~s})$ and the stage when its rate is approximately at its maximum $(t=1500 \mathrm{~s})$ when half of the sample's mass was volatilised. At the applied heating rate $\left(22^{\circ} \mathrm{C} / \mathrm{min}\right)$ a significant temperature difference can be observed, reaching approx. $40{ }^{\circ} \mathrm{C}$ between the gas phase in the vicinity of the sample's surface and the core of the sample.

The calculated porosity contours in the tyre sample and the streamlines in the reactor at the same time instants are shown in Figs. 4 and 5, respectively.

Simulation results indicate that spatial variation of porosity in the sample is not very significant (up to $10 \%$ ) during the whole process. Pyrolysis starts at the edges of the sample where the temperature is higher and the front of reaction forms, which is more or less smeared depending on the heating rate and stage of the process. The conversion front corresponds to porosity profile contours (isolines) moving towards the centre of the sample in the course of the pyrolysis process. The reaction zone extends throughout the whole sample and its porosity grows, while maintaining mild variation of the spatial profile.

Comparison of the gas phase stream lines shown in Fig. 5 for the two chosen times may illustrate increase of gas flow rate due to the production of volatiles, which is clearly visible in Fig. $5 \mathrm{~b}(t=1500 \mathrm{~s})$ for fully developed pyrolysis process, where some of the streamlines originate from the sample's region.

The calculated contours of mass fraction of the volatile products of tyre pyrolysis in the gas phase for the same run \#3, at the same time instants $(t=800 \mathrm{~s})$ and $(t=1500 \mathrm{~s})$ are shown in Figs. $6 \mathrm{a})$ and b), respectively. As the flow direction of nitrogen is from right (narrow inlet) to left (outlet) in Fig. 6, the mass fraction of volatile products at the outlet reaches approximately $1.5 \%$ at the beginning of the pyrolysis process $(t=800 \mathrm{~s})$ and $8 \%$ at $t=1500 \mathrm{~s}$, when the rate of the process is much higher in the considered case of run \#3 (see Fig. 2, final temperature $=455^{\circ} \mathrm{C}$ ). This also involves a proportional increase of the total mas flow rate of the gaseous products through the reactor. The total mass flow rate 


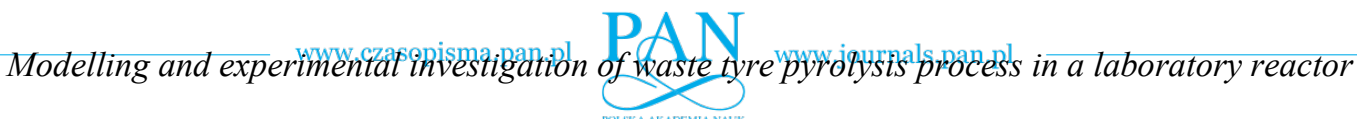

at the outlet increased by $6.6 \%$ between the two time instants. It can be also observed that some volatile products transported by molecular diffusion are present upstream of the sample.

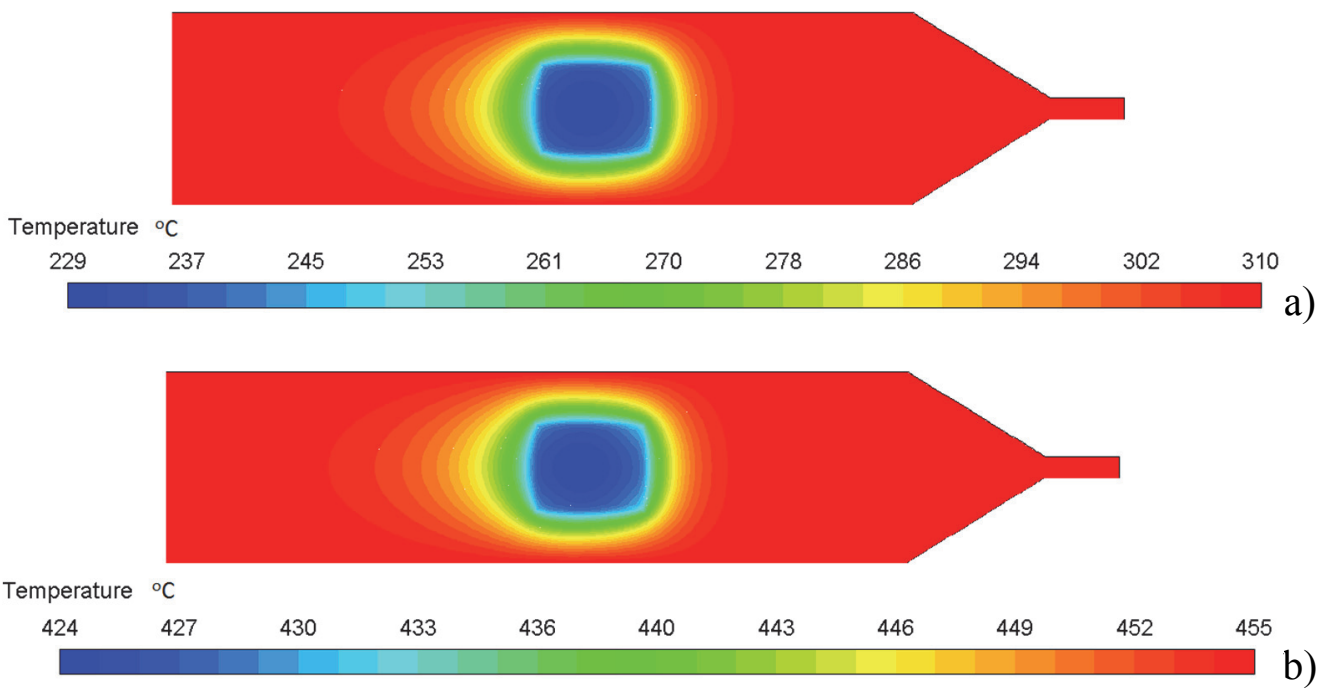

Fig. 3. Calculated contours of temperature $\left({ }^{\circ} \mathrm{C}\right)$ at times a) $t=800 \mathrm{~s}$ and b) $t=1500 \mathrm{~s}$ after process start-up (run \#3)
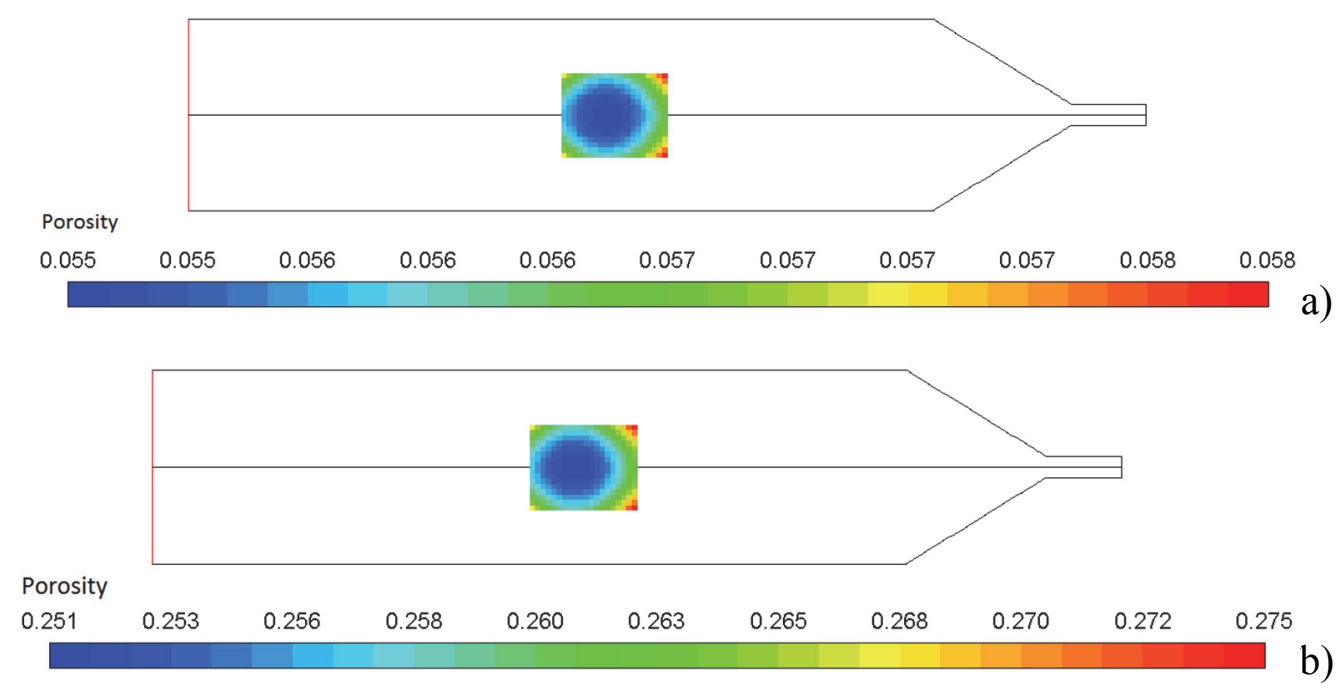

Fig. 4. Calculated contours of porosity (-) at times a) $t=800 \mathrm{~s}$ and b) $t=1500 \mathrm{~s}$ after process start-up (run \#3)

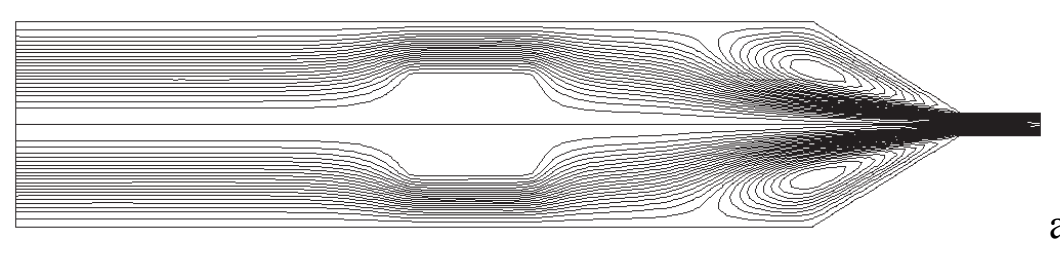

a)

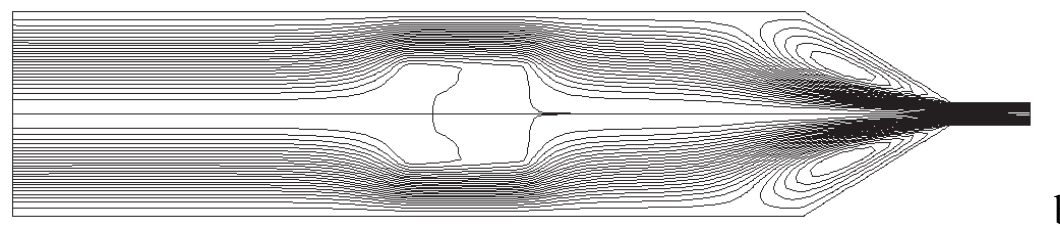

b)

Fig. 5. Calculated gas streamlines at times a) $t=800 \mathrm{~s}$ and b) $t=1500 \mathrm{~s}$ after process start-up (run \#3) 

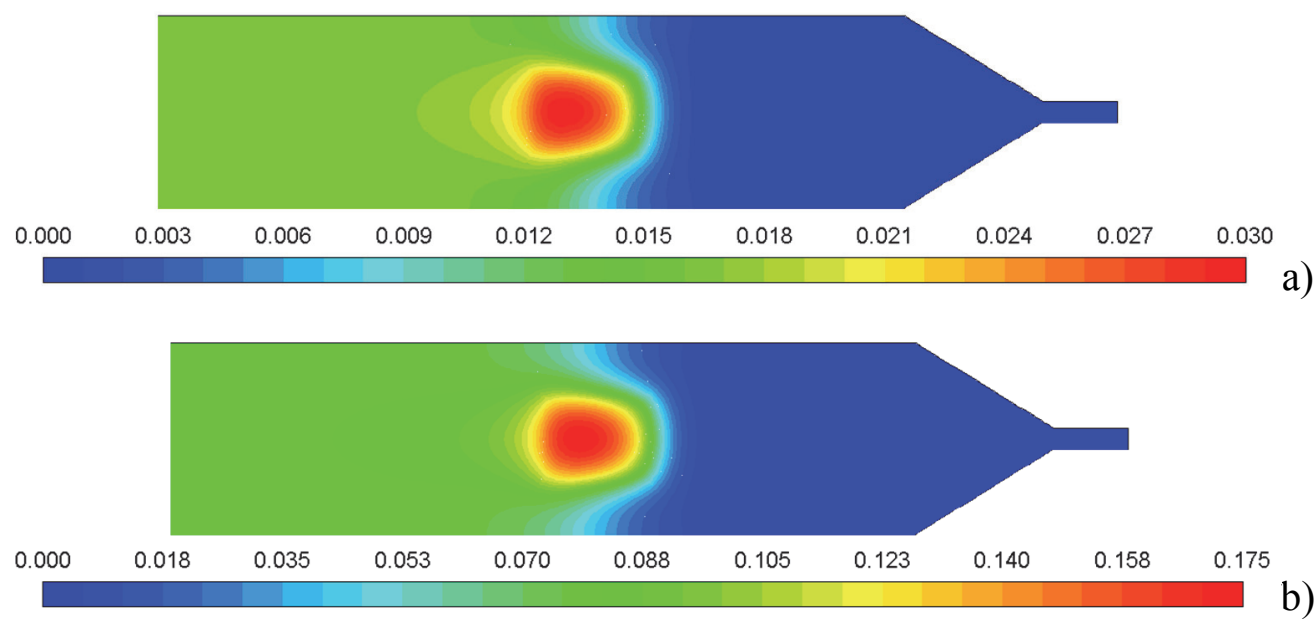

Fig. 6. Calculated contours of mass fraction of volatile pyrolysis products (-) at times a) $t=800 \mathrm{~s}$ and b) $t=1500 \mathrm{~s}$ after process start-up (run \#3)

\section{CONCLUSIONS}

The results of numerical simulation of the pyrolysis process based on the simplified kinetic model of car tyre pyrolysis, implemented within CFD software (ANSYS Fluent), are in satisfactory agreement with the experimentally measured relative mass loss of the tyre sample during pyrolysis carried out in a laboratory reactor.

The obtained results indicate the importance of heat and mass transfer phenomena during the pyrolysis of the rubber material. The evident inhomogeneity of porosity, temperature and consequently the decomposition rate developed during the process impose the requirement of using dedicated numerical methods (e.g. CFD tools) for modelling of the pyrolysis process in industrial conditions.

This project is co-financed from the resources of the National Centre for Research and Development and the European Union under European Regional Development Fund in accordance with UOD-DEM$1-217 / 001$.

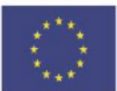

The author would like to acknowledge one of the reviewers for very helpful comments and enlightening suggestions.

\section{SYMBOLS}

$A \quad$ pre-exponential factor in Arrhenius equation, $1 / \mathrm{min}$

$C_{p} \quad$ specific heat, $\mathrm{J} /(\mathrm{kg} \cdot \mathrm{K})$

$D_{i} \quad$ mass diffusivity of component $i, \mathrm{~m}^{2} / \cdot \mathrm{s}$

E activation energy, $\mathrm{J} / \mathrm{mol}$

$f_{i} \quad$ mass yield of component (product lump) $i$

$g \quad$ gravity vector, $\mathrm{m} / \mathrm{s}^{2}$

$k \quad$ thermal conductivity, $\mathrm{W} /(\mathrm{m} \cdot \mathrm{K})$

$P \quad$ pressure, $\mathrm{Pa}$ 

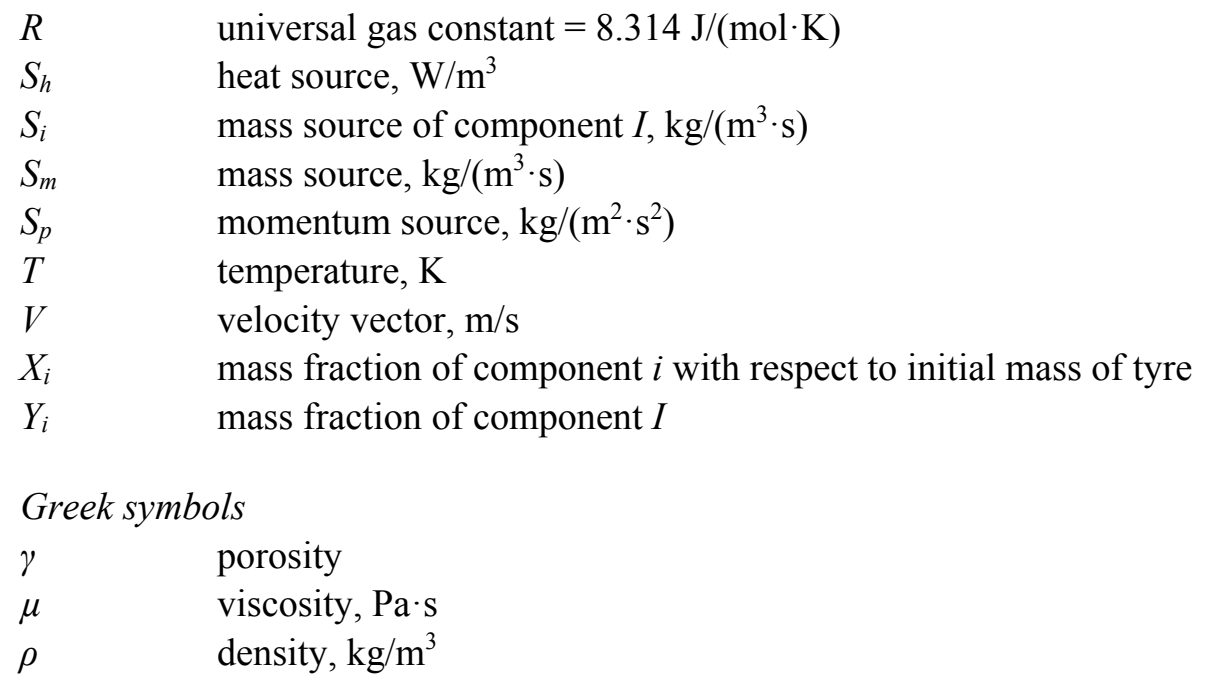

$\begin{array}{ll}\text { Subscripts } & \\ G & \text { noncondensable gaseous products } \\ L & \text { condensable vapour (liquid) products } \\ S & \text { solid remainder } \\ V & \text { volatile products (compounds) } \\ i & \text { component index }(i=\mathrm{A}, \mathrm{SBR}) \\ \text { eff } & \text { effective (in porous medium) } \\ p m & \text { porous medium }\end{array}$

\section{REFERENCES}

ANSYS Fluent Theory Guide, 2017. Ansys Inc., rel. 18.0., January 2017. Available at: www.ansys.com.

Antoniou N., Zabaniotou A., 2013. Features of an efficient and environmentally attractive used tyres pyrolysis with energy and material recovery. Renewable Sustainable Energy Rev., 20, 539-558. DOI: 10.1016/j.rser.2012.12.005.

Aylón E., Callén M. S., López J.M., Mastral A.M., Murillo R., Navarro M.V., Stelmach S., 2005. Assessment of tire devolatilization kinetics. J. Anal. Appl. Pyrolysis, 74, 259-264. DOI: 10.1016/j.jaap.2004.09.006.

Aylón E., Fernández-Colino A., Murillo R., Grasa G., Navarro M.V., García T., Mastral A.M., 2010b. Waste tyre pyrolysis: Modelling of a moving bed reactor. Waste Manage., 30, 2530-2536. DOI: 10.1016/j.wasman.2010.04.018.

Aylón E., Fernández-Colino A., Murillo R., Navarro M.V., García T., Mastral A.M., 2010a. Valorisation of waste tyre by pyrolysis in a moving bed reactor. Waste Manage., 30, 1220-1224. DOI: 10.1016/j.wasman.2009.10.001.

Bianchi M., Bortolani G., Cavazzoni M., De Pascale A., Montanari I., Nobili M., Peretto A., Tosi C., Vecci R., 2014. Preliminary design and numerical analysis of a scrap tires pyrolysis system. Energy Procedia, 45, 111120. DOI: 10.1016/j.egypro.2014.01.013.

Cherbański R., Wróblewski K., Molga E.J., 2016. Badanie procesu pirolizy zużytych opon samochodowych w reaktorze laboratoryjnym. Inż. Ap. Chem., 55 (1), 16-17.

Kaminsky W., Mennerich C., Zhang Z., 2009. Feedstock recycling of synthetic and natural rubber by pyrolysis in a fluidized bed. J. Anal. Appl. Pyrolysis, 85, 334-337. DOI: 10.1016/j.jaap.2008.11.012.

Lam K.-L., Gebreegziabher T., Oyedun A. O., Lee H. K. M. Hui C.-W., 2012. CFD study on fluidized bed pyrolyzers. Chem. Eng. Trans., 29, 661-666.

Lopez G., Olazar M., Aguado R., Elordi G., Amutio M., Artetxe M., Bilbao J., 2010. Vacuum pyrolysis of waste tires by continuously feeding into a conical spouted bed reactor. Ind. Eng. Chem. Res., 49, 8990-8997. DOI: 10.1021/ie1000604.

Machniewski P., Rudniak L., Molga E., 2016. Modelowanie procesu pirolizy odpadów gumowych. Inż. Ap. Chem., 55 (1), 28-29 (in Polish). 
Miranda M., Pinto F., Gulyurtlu I., Cabrita I., 2013. Pyrolysis of rubber tyre wastes: A kinetic study. Fuel, 103, 542-552. DOI: 10.1016/j.fuel.2012.06.114.

Mtui P., 2013. CFD modeling of devolatilization and combustion of shredded tires and pine wood in rotary cement kilns. Amer. J. Energy Engineering, 1, 51-55. DOI: 10.11648/j.ajee.20130105.11.

Niksiar A., Sohrabi M., 2014. Mathematical modeling of waste plastic pyrolysis in conical spouted beds: Heat, mass, and momentum transport. J. Anal. Appl. Pyrolysis, 110, 66-78. DOI: 10.1016/j.jaap.2014.08.005.

Olazar M., Lopez G., Arabiourrutia M., Elordi G., Aguado R., Bilbao J., 2008. Kinetic modelling of tyre pyrolysis in a conical spouted bed reactor. J. Anal. Appl. Pyrolysis, 81, 127-132. DOI: 10.1016/j.jaap.2007.09.011.

Queck A., Balasubramanian R., 2012. Mathematical modeling of rubber tire pyrolysis. J. Anal. Appl. Pyrolysis, 95, 1-13. DOI: 10.1016/j.jaap.2012.01.012.

Yang J., Tanguy P.A., Roy C., 1995. Heat transfer, mass transfer and kinetics study of the vacuum pyrolysis of a large used tire particle. Chem. Eng. Sci., 50, 1909-1922. DOI: 10.1016/0009-2509(95)00062-A.

Received 18 October 2016

Received in revised form 10 July 2017

Accepted 24 July 2017 